\title{
Poéticas do Urbano
}

Celia Maria Antonacci Ramos

Poéticas do Urbano é um texto sobre as pesquisas e ações do grupo de pesquisa "Poéticas do Urbano", da Universidade do Estado de Santa Catarina. Nosso objeto de investigação é a cidade - não como um grande objeto, mas como um modo de vida, de relações sociais, de exercício político e de sobrevivência diária. Interessa-nos a cidade-metrópole e suas transformações nos últimos anos. Priorizamos as novas cartografias e os espaços de globalização provenientes da chegada de novos sujeitos na cidade a partir das migrações dos anos 80 .

Palavras-chave

Urbanismo, cidade, arte, comunicação

Há no nosso cotidiano social e acadêmico um senso comum que nos diz pertencermos à era da informação e da comunicação. Tudo gira em torno da idéia de que os aparelhos tecnológicos de transmissão da informação possibilitam "novos tempos". Nessa onda tecnológica vem de arrastão a idéia da globalização e do pós-moderno na vida e na arte, expressa nesses novos meios e com possibilidades de outras estéticas. Tudo parece confluir e encontrar uma explicação ou solução para o conceito pós-moderno e seus aparatos virtuais. Vivemos assim os "Novos Tempos".

Stuart Hall abre seu ensaio The meaning of New Times com os seguintes questionamentos.

Quão novos são esses novos tempos? São eles a sombra de um Novo Anjo ou apenas o murmúrio de um velho? O que é novo neles? Como nos reportamos às suas tendências ou contradições? São eles progressivos ou regressivos?

E comenta: essas são algumas das questões do discurso ambíguo sobre os novos tempos. $^{1}$

Nosso objeto de investigação é a cidade - não como um grande objeto, mas como um modo de vida, de relações sociais, de exercício político e de sobrevivência diária. Interessanos a cidade-metrópole e suas transformações nos últimos anos. Guy Burgel, ao escrever 
sobre "La ville aujourd'hui", lembra-nos que menos de cinqüenta anos abalaram as certitudes milenares da cidade ${ }^{2}$

Planejada nas leis urbanistas de zoneamento, propostas no Congresso de Atenas, 1933, a cidade racionalizada passou a ser sinônimo de civilização, isto é, de previsão, de censura e de controle da informação, e também de espetaculosidade social. A história da cidade vai se firmando no poder do Estado, que divide e separa as zonas de trabalho, comércio, habitação e lazer. Tudo na cidade planejada é previsível e controlado. A partir daí, Habitar a cidade, diz Bernard Lamizette, é reconhecer o poder que a estrutura e, em particular, se submeter à censura que faz da informação difusa no espaço urbano uma informação socialmente e institucionalmente determinante como pertencente a uma cultura. ${ }^{3}$ Passados cinqüenta anos ou mais dos primeiros planejamentos urbanísticos, que priorizavam o zoneamento, percebemos que a má gestão desses planejamentos desestabilizou a harmonia proposta no projeto. Milton Santos comenta: houve a primazia do econômico sobre o político, do instrumental sobre a finalidade e do dinheiro sobre o homem. ${ }^{4}$ A obsolescência do trabalho rural e o conseqüente empobrecimento das cidades pequenas pela modernização da agricultura e dos serviços forçaram muitos brasileiros a migrarem diariamente para as cidades em desenvolvimento à procura de novos meios de subsistência econômica, social e intelectual. As cidades passaram, nos últimos cinqüenta anos, a receber uma grande aglomeração urbana e se transformaram no lugar da diversidade, do pluralismo cultural, do afrontamento, das oportunidades - oportunidades de trabalho, emprego, moradia, diversão, comunicação e de transgressão, mas também de escassez - de trabalho, de emprego, de moradia e de comunicação. A cidade é hoje esse conjunto de pessoas, necessidades, privilégios e heranças históricas. É o lugar da imprevisibilidade. Novas situações são impostas ao cotidiano rotineiro da cidade "certitude". Milton Santos percebia a cidade como um organismo vivo. Para ele,

Ao longo de seu processo, a cidade, organismo vivo, impõe solidariamente valores funcionais, mercantis e simbólicos às suas diversas frações. Novos lugares são chamados a novas funções, velhos lugares se renovam inteiramente ou parcialmente, sendo arrastados ou conservando relíquias. A cada momento histórico, cada pedaço da cidade evolui diferentemente. ${ }^{5}$ 
Como todo organismo vivo, a cidade é um todo que depende de cada parte. Os estudos sobre a cidade têm que ser sistêmicos, temos que levar em conta as novas exigências da modernidade traduzidas nos novos meios de trabalhar, transitar e habitar a cidade. Milton Santos ainda nos lembra que a vida de cada qual passa a ser definida pela vida de todos os outros. Os lugares - e os homens com eles - mudam rapidamente e muito brutalmente de significação. ${ }^{6}$

Interessa-nos assim pensar o que é novo na cidade nesses novos tempos. Quais são os novos sujeitos e códigos que cruzam a cidade tanto nos planejamentos administrativos e nas invasões capitalistas, quanto na necessidade de sobrevivência diária, de conquista de território para morar, trabalhar, se divertir e se manifestar. Enviar recados - ordens e protestos. A otimização capitalista acelera o nomadismo contemporâneo, aproximando e afastando as populações. Uns migram do campo para a cidade, outros do centro para a periferia. Uns migram por opção, conforto e instrução, outros por falta de opção, especialmente de trabalho e moradia. Os novos tempos - o "pós-moderno" - sequiestram a tradição e impõem novas estéticas para a cidade.

Segundo Stuart Hall, justamente com as tendências homogeneizantes da globalização, existe a "proliferação subalterna da diferença.(...) O eixo "vertical” do poder cultural, econômico e tecnológico parece estar sempre marcado e compensado por conexões laterais, o que produz uma visão de mundo composta de muitas diferenças locais. Nesse modelo, o clássico binarismo iluminista Tradicionalismo/Modernidade é deslocado por um conjunto disseminado de "modernidades vernáculas. ${ }^{7}$

A partir disso, percebemos especialmente a estrutura horizontal da sociedade, que compreende a massa populacional hoje em sua maioria itinerante, muitas vezes sem registro de trabalho, endereço fixo, inscrição política fixa e até mesmo registro de nascimento, apesar da sofisticação tecnológica da modernidade. Considerada anteriormente como minoria, hoje essa população aflora e se desloca nas cidades em um número considerável e inscreve nela seus modos de viver e, especialmente, de sobreviver. Criam habitações e estratégias de trabalho e lazer nas periferias ou nos vazios da cidade, nas fissuras do sistema. Criam formas inovadoras de habitar a cidade. Propõem novas estéticas à cidade. A respeito dessas migrações, diz Stuart Hall: 
Culturalmente elas não podem conter a maré da tecno-modernidade ocidentalizante. Entretanto, continuam a modular, desviar, "traduzir" seus imperativos a partir da base. Elas constituem o fundamento para um novo tipo de "localismo".(...) Esse "localismo"não é um mero resíduo do passado. É algo novo - a sombra que acompanha a globalização, mas retorna para perturbar e transtornar seus estabelecimentos culturais. ${ }^{8}$

Nelso Brissac, citando Rem Koolhaas, lembra que a globalização faz emergir cidades que garantem sua existência e produtividade apesar da quase total ausência de infra-estrutura. E continua: as deficiências dos planejamentos urbanos ou a má gestão dos mesmos gera sistemas alternativos engenhosos e críticos, capazes de garantir a eficácia em grande escala de dispositivos considerados informais ou ilegais. A globalização provém uma vasta gama de novas oportunidades para operar fora dos sistemas regulatórios. ${ }^{9}$

Operar fora dos sistemas regulatórios significa transgredir as normas vigentes, quer seja no trabalho, na vida, na comunicação e na arte. Significa interagir nas brechas do sistema, na contramão das regras pré-estabelecidas. Ainda Brissac nos lembra que $a$ originalidade e a espontaneidade na improvisação de moradias e equipamentos têm sido uma marca da população marginalizada. Hélio Oiticica destacou o potencial plástico e perceptivo das favelas, com seus espaços que se misturam, feitos de conexões e transparências. ${ }^{10}$

Preservar a cultura é uma condição humana indispensável. Monumentos, arquiteturas, pinturas, gravuras e, mais contemporaneamente, a fotografia e os vídeos fixam e transmitem nossos sentimentos de pertencimento a uma cultura. Personagens de nossa história nacional são memorados nos ritos de calendário, no nome das ruas, nas placas comemorativas. Textos que se impõem como patrimônios da memória coletiva oficial a ser transmitida na história da nação. Essa memória coletiva oficial tem seu lugar e respeito na história da cidade, mas não é única. Outras vozes também constroem a cidade e insistem em serem ouvidas. Hoje percebemos que a escrita da cidade depende de seus moradores.

Levando em conta os "localismos" e as contradições da globalização, tomamos como base de referência a cidade de Florianópolis, que como tantas outras cidades no Brasil recebeu nos últimos anos um fluxo migratório significativo. Percebemos nessa cidade especialmente a espontaneidade comunicativa dos novos sujeitos deslocados da mídia oficial. 
O grupo "Poéticas do Urbano" vem investigando as tessituras ordinárias da vida cotidiana, as subjetividades, o potencial estético e os modos de comunicação emergentes na cidade globalizada. Nosso foco de atenção é a história de Florianópolis conservada nos álbuns de família e os rituais surgidos nos novos encontros, os grafites planejados ou aleatórios escritos nos muros da cidade e os camelôs e ambulantes com suas inovadoras territorialidades.

Assim, não nos interessam os sujeitos sociais historicamente determinados e suas expressões já oficializadas nos códigos dominantes, mas os novos sujeitos negligenciados pelas políticas dominantes e seus modos de produção cultural e ideológica expressos nos seus modos de habitar a cidade.

Objetivando entender as tendências ou contradições da modernidade, e a elas nos reportar, vimos agenciando uma série de pesquisas e ações no Município de Florianópolis.

A exemplo das derivas situacionistas, o grupo percorreu algumas vezes a cidade e grafitou ou colocou pequenos adesivos em forma de placa de trânsito com a frase "A Cidade Não Pára". Na ocasião, inquirimos as pessoas sobre essa advertência.

Em novembro de 2005, durante o seminário Cidade Memória Fotografia, o grupo instalou no Largo da Alfândega, praça central de Florianópolis, uma máquina fotográfica, modelo Pin Hole, com capacidade para abrigar até 10 pessoas em seu interior e perceber a fotografia em tempo real. Na parte externa da caixa, através de pequenos orifícios, era possível observar fotos antigas de Florianópolis, estabelecendo assim uma atenção à fotografia como um registro de memória.

Objetivando mapear as novas cartografias da cidade, entrevistamos alguns moradores da comunidade "Nova Esperança", bairro de periferia estabelecida desde 1998. A partir dos álbuns de família, os moradores narram suas trajetórias pessoais na formação desse bairro.

Atualmente, estamos pesquisando os camelôs e ambulantes fixados ou perambulantes no centro histórico da cidade. Nosso objetivo é perceber e dar a perceber as políticas e poéticas dos camelôs e ambulantes em relação à cidade, e os relacionamentos sociais, culturais, políticos e amorosos estabelecidos nos encontros de trabalho nas ruas da ciddade. 
Paralelo à pesquisa e às ações, desenvolvemos textos fotográficos sob a orientação do professor fotógrafo Cláudio Brandão, coordenador adjunto do projeto. Como divulgação e reflexão das pesquisas, organizamos seminários com pesquisadores afins e organizamos um site com toda a documentação das pesquisas e ações do grupo, e um catálogo impresso que publicam os resultados mais relevantes do projeto.

Esperamos que os estudos acadêmicos se encontrem com o conhecimento das pessoas que aqui circulam e deixam sua história. $\mathrm{O}$ ensino acadêmico especializado por si só já não mais encontra suficiência para conhecer e participar de seu momento histórico. É preciso criar mecanismos de diálogo com outras formas de conhecimento e com outros sujeitos sociais, pois como lembra Milton Santos, $\mathrm{Na}$ sociedade de informação a relação entre as pessoas cria riquezas. ${ }^{11}$

As abordagens acadêmicas, artísticas ou filosóficas não são pensamentos ou expressões vedadas, mas atentas e participativas no contexto social do qual fazem parte. O que importa nas questões atuais sobre sociedade e estética não é definir conceitos e classificar obras, mas, como nos adverte Stuart Hall, quando se reporta as discussões sobre os "Novos Temos",

Seria melhor perguntar, não porque os novos tempos representam uma série de respostas definitivas a uma série de questões ou ainda uma maneira clara de resolver a ambigüidade inerente nessa idéia, mas por que eles estimulam a esquerda a abrir um debate sobre como a sociedade está mudando e oferecer novas descrições de análise da condição social que procura transcender e transformar. ${ }^{12}$

Nessa medida, o projeto 'Poéticas do Urbano", através das pesquisas junto aos novos sujeitos da cidade, dos textos publicados no catálogo e no site, dos seminários e das ações na cidade, objetiva propor um debate sobre as configurações da cidade contemporânea de forma a reconhecermos suas problemáticas e encontrarmos juntos formas de convivência cultural e social. 
${ }^{1}$ Stuart Hall,. The Meaning of New Times, in Critical Dialogues in Cultural Studies, David Marley e Kuan -Hsing Chen, London, New York, Routledge, 2001,p. 223.

${ }^{2}$ Guy Burgel, La Ville aujourd'hui, Paris, Hachete, 1993, p. 9

${ }^{3}$ Bernard Lamizet, lê Sens de la Ville.. Paris, L'Harmattan, 2002, p. 26.

${ }^{4}$ Milton Santos, O País Distorcido . São Paulo, Publifolha, 2002, p. 85.

${ }^{5}$ Idem, p. 24.

${ }^{6}$ Milon Santos, o País Distorcido. São Paulo, Publifolha, 2002, p.

${ }^{7}$ Liv Sovik, org. Stuart Hall. Da Diáspora, Identidades e Mediações Culturais. Belo Horizonte, Huamnitas, 2003, p. 60.

${ }^{8}$ Idem, ibidem, p. 60.

${ }^{9}$ Nelson Brissac, Catálogo Arte/Cidade. As Máquinas de Guerra Contra os Aparelhos de Captura. s/d.

${ }^{10}$ Idem, Ibidem.

${ }^{11}$ Santos, Milton. O País Distorcido. Publifolha, 2002,p. 37.

${ }^{12}$ Hall, Stuart, Op. Cit., 223. 